\title{
Rancang Bangun Hand Tracking Glove sebagai Antarmuka untuk Game Rehabilitasi
}

\author{
Milla Rahmadiva, Achmad Arifin, Muhammad Hilman Fatoni, dan Siti Halimah Baki \\ Departemen Teknik Biomedik, Institut Teknologi Sepuluh Nopember (ITS) \\ e-mail: arifin@bme.its.ac.id
}

\begin{abstract}
Abstrak-Stroke merupakan suatu kondisi yang terjadi ketika suplai darah menuju otak tersumbat. Penyakit ini merupakan salah satu penyebab kematian. Sebanyak $30 \%$ hingga $66 \%$ pasien stroke mengalami kelumpuhan pada lengan yang menyebabkan mereka kesulitan melakukan aktivitas sehari-hari [1]. Salah satu dampak dari kelumpuhan pada lengan adalah kelainan sistem gerak pada jari. Pada penelitian ini diusulkan sebuah glove yang tidak hanya mampu menggantikan goniometer jari untuk mengukur range of motion, tetapi juga bisa menjadi alat rehabilitasi pasien pasca stroke melalui serious game yang mampu memotivasi agar range of motion jari pasien bertambah. Perancangan glove dilakukan dengan menyusun sensor secara array pada tiap jari sehingga bisa mengukur sudut sendi secara bersamaan. Pengujian glove terdiri dari pengujian hardware dan software. Hasil menunjukkan error yang kecil antara pembacaan glove dengan pembacaan goniometer jari sebagai alat yang sudah umum digunakan untuk mengukur Range of motion (ROM) jari. Mean squared error yang dihasilkan dari pengukuran dengan glove adalah 0.68 .
\end{abstract}

Kata Kunci-Hand Tracking Glove, Rehabilitasi, Post-Stroke, Sensor Array

\section{PENDAHULUAN}

$\mathrm{S}_{\mathrm{n}}^{\mathrm{T}}$ TROKE adalah penyakit berbahaya yang dapat menyebabkan kematian pada penderita. Stroke merupakan penyebab kematian paling sering kedua di seluruh dunia, sebanyak 6,2 juta kematian (WHO, 2013). Di Amerika, stroke terjadi setiap 40 detik. Kegiatan yang dilakukan dengan tangan contohnya makan, minum, dan mengambil suatu benda. Seringkali penderita stroke memiliki kelumpuhan parsial pada satu sisi tubuh dan gerakannya dapat sangat terbatas pada tangan atau bagian tubuh yang terkena stroke [2]. Dari semua pergerakan yang dilakukan, melibatkan range of motion pergerakan suatu anggota tubuh tertentu. Pada pasien stoke, range of motion ini akan sangat terbatas. Sehingga, perlu dilakukan latihan yang sifatnya intensive dan repetitive untuk membantu pasien pulih seperti sedia kala.

Rehabilitasi pasien stroke dapat dilakukan dengan beberapa cara. Salah satunya adalah melalui electrical stimulation, dan juga exoskeleton. Saat ini, exoskeleton yang digunakan untuk membantu bagian tubuh pasien stroke untuk bergerak telah diintegrasikan dengan arm robot. Namun, meskipun telah melalui banyak prosedur rehabilitasi dan pengobatan, pasien tidak boleh berhenti latihan karena bisa menyebabkan kemampuan bergeraknya menurun lagi. Oleh karena itu, jika

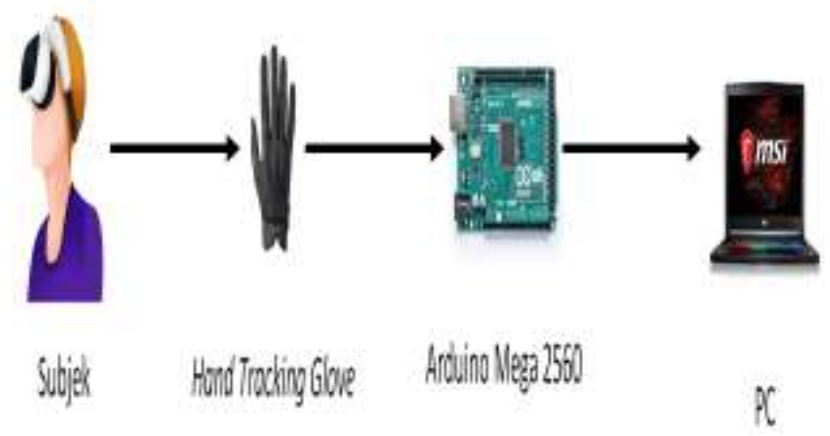

Gambar 1. Blok diagram sistem secara keseluruhan

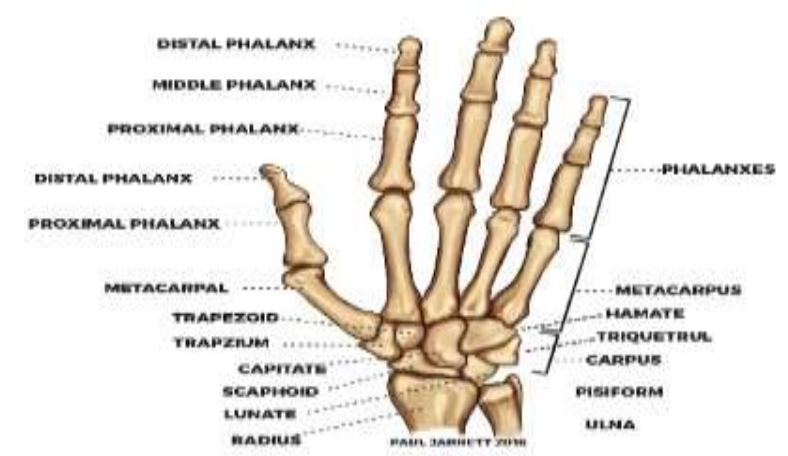

Gambar 2. Anatomi tangan manusia (Jarrett, 2016)

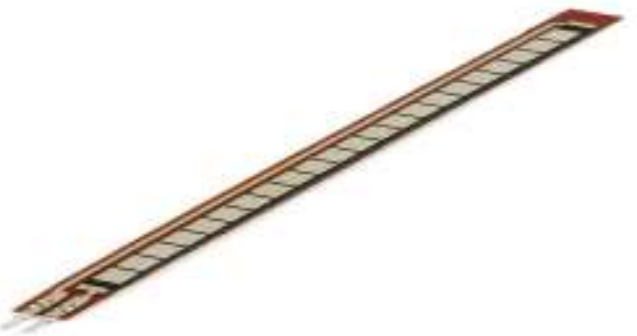

Gambar 3. Flex sensor 4.5 inch (Sparkfun)

setelah melakukan beberapa prosedur terapi dan berobat penderita stroke lolos dari kematian, bukan berarti masalahnya selesai. Justru pasien harus dilatih lagi agar range of motion bagian tubuh pasien bisa kembali normal. Latihan yang berulang-ulang itu bertujuan untuk mendorong perubahan neuroplastis otak.

Salah satu cara untuk mengatasi rasa bosan pasien adalah dengan memanfaatkan visual feedback untuk mengurangi rasa 


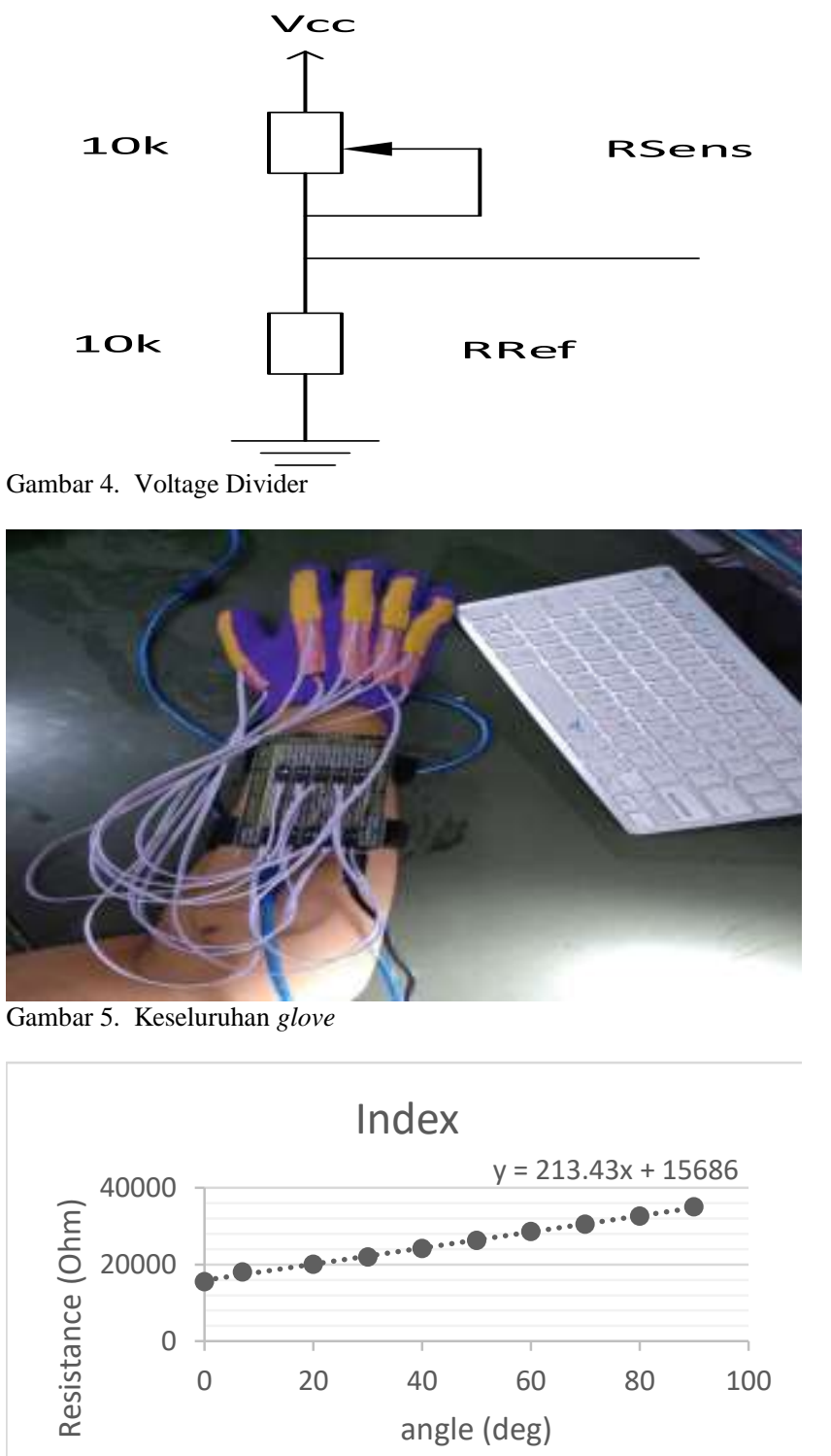

Gambar 6. Perubahan sudut terhadap resistansi index finger

bosan sehingga rehabilitasi terasa lebih memotivasi seperti game [3], dan pasien bisa lebih larut dalam rehabilitasinya. Teknologi yang dapat diimplementasikan dalam rehabilitasi adalah video game. Apalagi, dengan adanya visual feedback dan visual environment yang disajikan, akan lebih menarik dan dengan ditambah sensor yang digunakan pengguna, maka pasien akan lebih memiliki perasaan high degree of control.

Sistem dalam rehabilitasi ini terdiri dari glove untuk mengambil data range of motion pasien yang juga menjadi ukuran perkembangan dari pasien. Penggunaan glove ini bertujuan untuk mengukur sudut range of motion sendi dan juga sebagai alat agar pasien memiliki high degree of control dalam game.

\section{DESAIN}

\section{A. Blok Diagram Sistem}

Secara umum, sistem terdiri dari perangkat keras dan

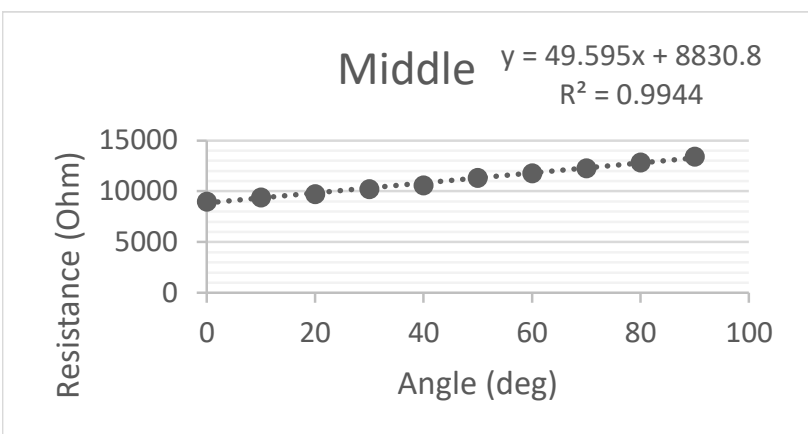

Gambar 7. Perubahan sudut terhadap resistansi middle finger

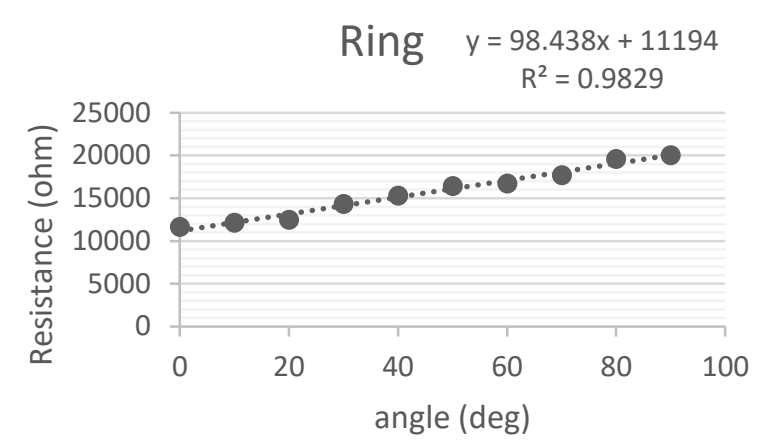

Gambar 8. Perubahan sudut terhadap resistansi ring finger

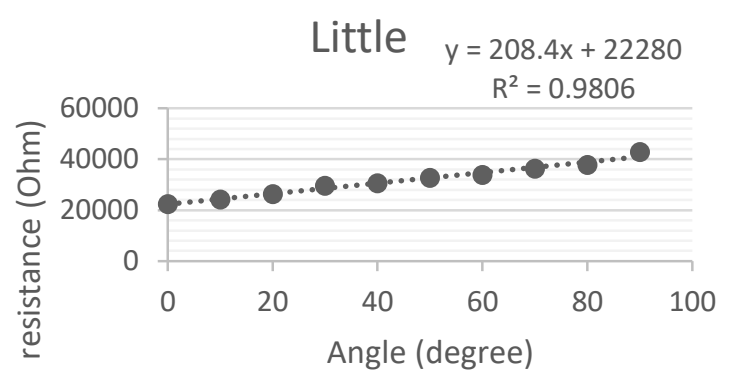

Gambar 9. Perubahan sudut terhadap resistansi little finger

perangkat lunak seperti pada Gambar 1. Perangkat keras berupa Personal Computer (PC), Mikrokontroler Arduino, serta sistem dari glove sendiri. Perangkat lunak terdiri dari program arduino. Subjek akan menggunakan glove yang sudah dipasangi 10 buah flex sensor pada bagian jari-jarinya. Sensor Flex akan membaca sudut pergerakan dari jari-jarinya. Pembacaan sensor flex akan dikirimkan secara serial dari Arduino ke PC. Perkembangan pasien akan dinilai melalui durasi dari tiap permainan. Jika ROM dan besarnya sudut jari pasien meningkat, berarti pasien mulai membaik.

\section{B. Anatomi Tangan Manusia}

Berdasarkan strukturnya, tangan manusia terdiri dari 29 tulang yang terkoneksi dengan beberapa sendi seperti pada Gambar 2. Pembagian yang paling sederhana, membedakan 3 bagian dari tangan : (a)the wrist (Latin: carpus); (b) the palm (Latin: metacarpus); (c)fingers (Latin: digiti manus). Pergelangan tangan (wrist) terdiri dari delapan tulang karpal kecil - schapoid, lunate, triquetrum, pisiform, trapezium, trapezoid, capitate and hamate, yang tersusun di tiga kolom : 


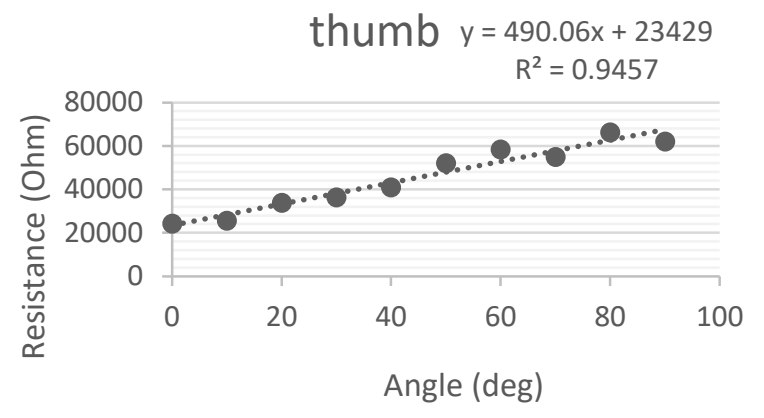

Gambar 10. Perubahan sudut terhadap resistansi thumb

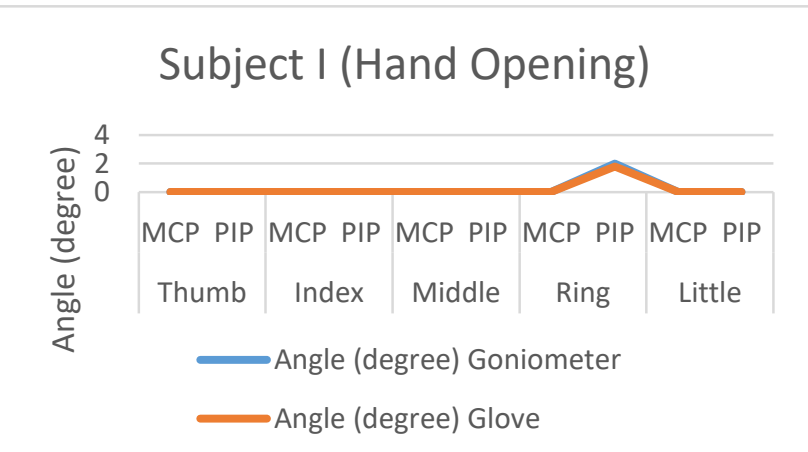

Gambar 11. Subyek I (Hand Opening)

\section{Subject I (Hand Closing)}

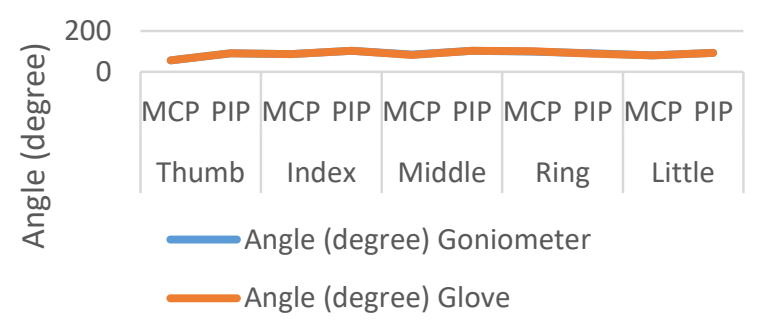

Gambar 12. Subyek I (Hand Closing)

the radial scaphoid, the lunate and ulnar triquetral column. Fungsi utama dari wrist adalah untuk mengkoneksikan tangan dengan lengan bawah. Tulang metacarpal dimasukkan ke kelompok tulang panjang. Setiap tulang terdiri dari base yang terartikulasi dengan tulang carpal. Kepala dan badan tulang metacarpal tersambung dengan jari-jari. Jari-jari meliputi phalanges - dari index kedua ke lima (kecil) memiliki tiga phalanges - proximal, intermediate, dan distal. Dimana thumb adalah pengecualian. Dalam penelitian ini yang diperlukan adalah sendi dari jari manusia. Sendi yang akan dibaca sudutnya adalah metacarpophalangeal (MCP/MP), Proximal interphalangeal (PIP), dan Distal interphalangeal (DIP) untuk semua jari selain thumb. Sedangkan untuk ibu jari yang digunakan adalah sudut MCP dan interphalangeal (IP).

Pergerakan tangan terdiri dari 8 tulang carpal kecilscaphoid, lunate, triquetrum, pisiform, trapezium, trapezoid, capitate dan hamate, tersusun dalam 3 kolom : radial scaphoid, lunate dan kolom ulnar triquetral[4]. Fungsi utama dari tulang carpal kecil adalah untuk menghubungkan antara tangan

\section{Subyek II (Hand Opening)}

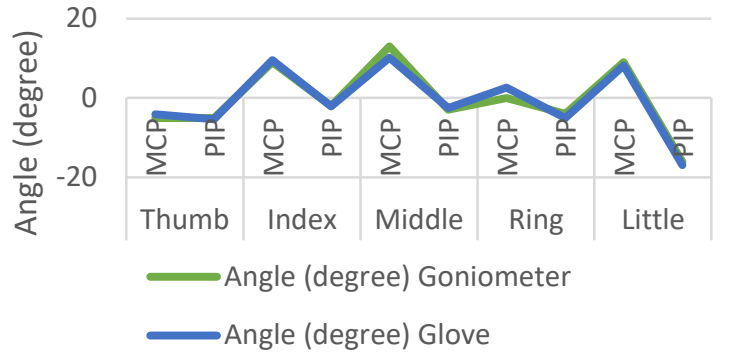

Gambar 13. Subyek II (Hand Opening)

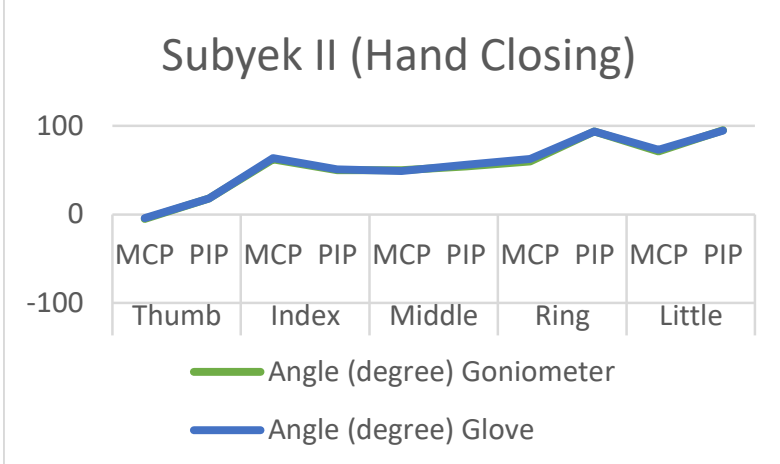

Gambar 14. Subyek II (Hand Closing)

dengan lengan bawah. Tulang metacarpal, berdasarkan strukturnya, dikelompokkan menjadi tulang panjang. Karena sendi pada jari, tangan dapat melakukan gerakan kompleks. Terdapat beberapa sendi yang membentuk tangan seseorang terdiri dari : (a) Radiocarpal Sendi; (b) Midcarpal Memungkinkan jari untuk bergerak fleksi dan ekstensi; (c) Intercarpal. Antara tulang carpal dan metacarpal, terdapat 5 sendi carpometacarpal (CMC), dan hanya salah satu dari sendi itu, yaitu CMC ibu jari, memiliki ruang gerak yang luas, yaitu termasuk fleksi dan ekstensi, abduction dan adduction, circumduction, dan opposition. Sendi antara phalanges dinamakan sendi interphalangeal. Setiap jari dari jari kedua hingga kelima memiliki sendi interphalangeal-proximal dan distal, dimana pada ibu jari, artikulasi hanyaterdapat di antara proximal dan distal karena ibu jari memiliki sedikit intermediate phalanx. Sendi-sendi ini memfasilitasi pergerakan fleksi dan ekstensi dari phalanges.

\section{Hardware}

PC yang digunakan memiliki spesifikasi RAM 8 GB, processor Core i7, dan untuk memberikan game environment yang lebih baik, digunakan GTX 1060 VR Ready. PC ini akan berkomunikasi secara serial dengan Arduino Mega 2560. Arduino MEGA 2560 adalah sebuah board mikrokontroler yang menggunakan ATmega2560. Rate data dalam bits per second (baud) untuk pengiriman data secara serial adalah : 300 , 600, 1200, 2400, 4800, 9600, 14400, 19200, 28800, 38400, 57600 , or 115200 . Dalam penelitian ini digunakan baud rate 9600. Flex sensor yang digunakan adalah produk dari Spectra Symbol. Flex sensor digunakan sebagai komponen untuk 
Tabel 1.

Spesifikasi elektrik flex sensor

\begin{tabular}{l}
\hline \multicolumn{1}{c}{ Spesifikasi Elektrik } \\
\hline Flat Resistance: $25 \mathrm{~K}$ Ohms \\
Resistance Tolerance: $\pm 30 \%$ \\
Bend Resistance Range: $45 \mathrm{~K}$ to $125 \mathrm{~K}$ Ohms \\
Power Rating : 0.50 Watts continuous. 1 Watt Peak \\
\hline \hline
\end{tabular}

Tabel 2 .

Spesifikasi mekanik flex sensor

\begin{tabular}{l}
\multicolumn{1}{c}{ Spesifikasi mekanik flex sensor } \\
\hline \hline Life cycle: $>1$ million \\
Height : $0.017 "$ \\
Temperature Range : -35 to +80 \\
\hline \hline
\end{tabular}

Tabel 3.

Persamaan linear semua flex sensor PIP

\begin{tabular}{cccc}
\hline \hline Flex Sensor & $\begin{array}{c}\text { Sudut } \\
(\text { deg })\end{array}$ & $\begin{array}{c}\text { Resistansi } \\
(\text { Ohm })\end{array}$ & Persamaan \\
\hline Thumb & 0 & 37860 & $\mathrm{y}=159.11 \mathrm{x}+$ \\
& 90 & 52180 & 37860 \\
Index_PIP & 0 & 25500 & $\mathrm{y}=407.23 \mathrm{x}+$ \\
& 90 & 62151 & 25500 \\
Middle_PIP & 0 & 25500 & $\mathrm{y}=365.97 \mathrm{x}+$ \\
& 90 & 58437 & 25500 \\
Ring_PIP & 0 & 26310 & $\mathrm{y}=356.97 \mathrm{x}+$ \\
& 90 & 58437 & 26310 \\
Little_PIP & 0 & 22500 & $\mathrm{y}=399.3 \mathrm{x}+$ \\
& 90 & 27876 & 22500 \\
\hline \hline
\end{tabular}

Tabel 4.

Perbandingan tegangan yang dibaca Arduino dan Avometer

\begin{tabular}{cccccc}
\hline \hline Finger & Joint & Pin & $\begin{array}{c}\text { Tegangan } \\
\text { Arduino } \\
\text { (Volt) }\end{array}$ & $\begin{array}{c}\text { Tegangan } \\
\text { Avometer } \\
\text { (Volt) }\end{array}$ & Selisih \\
\hline thumb & CMC & A0 & 0.15 & 0.155 & 0.005 \\
index & MP & A1 & 0.2 & 0.209 & 0.009 \\
& MCP & A2 & 0.45 & 0.45 & 0 \\
middle & MCP & A3 & 0.2 & 0.209 & 0.009 \\
& PIP & A5 & 0.24 & 0.243 & 0.003 \\
& MCP & A6 & 0.2 & 0.205 & 0.005 \\
& PIP & A7 & 0.2 & 0.37 & 0 \\
& MCP & A8 & 0.35 & 0.204 & 0.004 \\
& PIP & A9 & 0.2 & 0.205 & 0.005 \\
\hline \hline
\end{tabular}

membaca sudut sendi jari dikarenakan ketahanan sensor yang baik dan fleksibilitas sensor tersebut dapat dilihat pada Tabel 1. Spesifik mekanik flex sensor data dilihat pada Tabel 2. Flex sensor dikoneksikan dengan tegangan supply +5VDC dan satu kaki sensor yang lain di-grounded. Penataan letak flex sensor diletakkan di atas setiap sendi jari. Agar pembacaan sudut bending sensor tepat, titik tengah sensor diatur agar berada tepat di atas setiap sendi jari. Dimana pada penelitian ini, sendi yang difokuskan adalah MCP dan PIP. Flex sensor yang digunakan berjumlah sepuluh dengan panjang 4.5 inch sebanyak tiga buah dan 2.2 inch sebanyak tujuh buah. Untuk sensor yang memiliki panjang 4.5 inch diletakkan di atas sendi metacarpophalangeal (MCP/MP), dan sensor dengan panjang 2.2 inch diletakkan di atas sendi Proximal interphalangeal (PIP), ditumpuk dengan sensor pada sendi MCP yang sudah dibatasi dengan kain. Agar tidak menggunakan banyak kabel, penggunaan shield untuk Arduino dimanfaatkan. Sehingga, ketika digunakan subjek tidak merasa repot karena printed circuit board (PCB) yang terpisah dari Arduino. Pada bagian bawah akrilik Arduino dibuatkan sabuk elastis untuk mengikatkan Arduino pada lengan subjek. Ilustrasi lengkap hardware ditunjukkan pada Gambar 5.

\section{Sensor Reading}

Sensor yang paling banyak digunakan untuk pengukuran sudut dengan mempertimbangkan fleksibilitas dan ketahanannya terhadap lingkungan adalah flex sensor seperti Gambar 3.. Untuk membaca satu sudut digunakan prinsip pembagi tegangan. Basic voltage divider digunakan untuk koneksi rangkaian antara mikrokontroler dan sensor flex seperti pada Gambar 4. Untuk mencari $V_{\text {out }}$ bisa digunakan rumus pada Persamaan (1) [5]. Perhitungan pembagi tegangan ini akan digunakan untuk pembacaan sudut jari tepatnya untuk sudut sendi PIP.

$$
V_{\text {out }}=\frac{R_{\mathrm{re}} f}{R_{\text {sens }}+R_{\mathrm{re}} f}
$$

\section{E. Software}

Ada tiga software yang digunakan untuk penelitian ini. Arduino IDE, dan RAD Strudio 10.1[6]. RAD Studio 10.1 digunakan untuk mengolah data range of motion dan untuk mencari kecepatan sudut. Persamaan yang digunakan untuk mencari kecepatan sudut seperti yang ditunjukkan pada (2).

$$
\omega=\frac{\Delta \theta}{\Delta t}
$$

$\omega$ menunjukkan kecepatan sudut, $\theta$ menunjukkan perubahan sudut, dan $t$ menunjukkan delta waktu dari besar sudut yang sekarang dikurangi waktu sudut sebelumnya. Frekuensi sampling ADC yang digunakan untuk membaca bending sensor didesain menjadi $10 \mathrm{~Hz}$ menggunakan timer interrupt. Sebelum dimasukkan ke dalam game engine, agar virtual hand di dalam game engine tidak bergetar dan pergerakannya halus, ADC harus terlebih dahulu dilakukan smoothing. Algoritma yang digunakan untuk ADC smoothing adalah Responsive Analog yang telah dimodifikasi.

\section{PENGUJIAN SISTEM}

\section{A. Hardware}

Untuk mengkalibrasi flex sensor, sensor harus ditekuk menggunakan busur dan diukur resistansinya menggunakan avometer, kemudian dicatat. Dari data bending yang didapatkan, dicari persamaan linear menggunakan rumus persamaan garis linear (3). Persamaan yang didapatkan ini yang kemudian akan dimasukkan ke dalam program. Pada Gambar 6 hingga Gambar 10 ditunjukkan hubungan ntara perubahan sudut dengan perubahan resistansi setiap sensor yang linear. Sebelum digunakan rumus garis linear yang telah ditemukan, pembacaan ADC harus stabil dulu agar nilai sudut yang 
terhitung benar. Persamaan linear untuk seluruh flex sensor 2.2 inch sendi PIP ditunjukkan pada Tabel 3. Perbedaan antara pencarian persamaan linear dari beberapa flex sensor sebelumnya adalah hanya digunakan dua sudut untuk flex sensor sendi PIP.

$$
(y-y 1)=\frac{(y 2-y 1)}{(x 2-X 1)}(x-x 1)
$$

\section{B. Software}

Untuk smoothing ADC agar objek yang dikontrol dengan glove stabil dan hanya bergerak jika ada gerakan, maka digunakan metode Responsive Analog yang dimodifikasi terlebih dahulu. Sebelum menggunakan metode Responsive Analog yang telah dimodifikasi, diuji terlebih dahulu apa tegangan yang terbaca Arduino dan avometer sudah sama karena bukan nilai raw ADC yang digunakan. Hasil perbandingan antara tegangan yang terbaca Arduino dengan avometer Pada Tabel 4, terlihat selisih antara tegangan yang dibaca avometer dengan Arduino sedikit. Berarti, pembacaan ADC sudah benar dan bisa digunakan persamaan linear yang telah ditemukan untuk mencari sudut bending dari flex sensor. Selanjutnya, glove bisa digunakan untuk dijadikan goniometer dan game controller dalam waktu bersamaan.

\section{HASIL}

Glove yang telah dirancang bangun akan dibandingkan dengan goniometer jari untuk meyakinkan bahwa hasil pengukuran yang didapatkan dengan flex sensor bisa dipercaya karena memiliki selisih hasil yang kecil atau bahkan persis dengan sudut yang didapatkan jika dilakukan pengukuran dengan menggunakan cara manual yang umum yaitu dengan menggunakan goniometer jari. Terdapat dua kondisi yang digunakan untuk membandingkan glove dengan goniometer jari. Pada saat hand opening (semua jari ekstensi) dan saat grasping (all fingers were completely curled). Gerakan ini dilakukan karena merupakan gerakan elemental movement yang menunjukkan kondisi tangan pasien stroke [7]. Percobaan ini dilakukan pada dua Subyek dengan Subyek I normal mengalami finger stiffness. Subyek I berusia 22 tahun dengan kondisi jari yang normal dan tidak pernah mengalami injury sebelumnya. Subyek diminta untuk melakukan posisi hand opening kemudian hand closing. Hasil perbandingan untuk kondisi idle hand dan hand closing Subyek I berada pada Gambar 11 dan Gambar 12. Sedangkan untuk Subyek II pada Gambar 13 dan Gambar 14.

\section{PEMBAHASAN}

Subyek I dan Subyek II, ternyata memiliki selisih yang lebih besar untuk Subyek II. Selisih yang lebih besar bisa terjadi karena titik tengah dari flex sensor berubah pada saat digunakan Subyek II. Secara ukuran jari, Subyek II memiliki ukuran jari yang lebih kecil dibandingkan dengan Subyek I. Namun, dalam hal flex sensor, yang paling mempengaruhi adalah diameter kelengkungan sensor. Partikel bahan flex sensor ketika menekuk persebarannya akan dipengaruhi pergeseran yang dihasilkan dan dipengaruhi oleh diameter bidang yang berada di bawah flex sensor, dalam yang dalam kasus ini adalah diameter sendi Subyek. Selain itu, perbedaan yang terlihat antara Subyek I (22 tahun) dan Subyek II (67 tahun) yang mengalami kaku jari adalah, Subyek II memiliki lebih banyak hiperekstensi meskipun pada saat posisi idle jika dibandingkan dengan Subyek I.

Meskipun selisihnya lebih banyak dibandingkan dengan Subyek I yang memang titik tengahnya sama dengan titik tengah sensor saat dilakukan pengukuran resistansi sensor dengan avometer. Berarti, error yang terjadi pada pengukuran Subyek II diakibatkan pergeseran titik tengah yang kurang pas berada di atas sendi tiap jarinya.

Pada kedua Subyek, yang paling sering terjadi error adalah pada pengukuran sensor untuk Ring MCP. Jika dilihat dari kejadian nyata saat pengukuran, seseorang ketika diperintahkan untuk memposisikan jarinya untuk netral, tiap individu berbeda-beda, terutama untuk knuckle Ring MCP. Terdapat individu yang memposisikan netral jarinya biasa saja, jempolterdapat yang terlalu bersemangat. Begitu juga pada saat menggenggam terdapat yang biasa saja dan terdapat yang terlalu kuat. Pada saat menggenggam, jari yang masih memiliki ruang untuk menekuk lagi adalah Ring.

\section{KESIMPULAN}

Telah dirancang sebuah glove bisa diintegrasikan dengan komputer dan game melalui komunikasi serial. Glove yang telah dirancang mampu membaca ROM seperti goniometer jari dengan mean squared error sebesar 0.68 untuk masing-masing posisi jari. Akurasi dari flex sensor dipengaruhi oleh pergeseran titik tengah dari sensor. Perbedaan akurasi setiap subjek bisa terjadi dikarenakan panjang jari seseorang yang berbeda sehingga letak sendi subyek juga tidak bisa selalu mengikuti titik tengah dari sensor. Untuk bahan glove yang digunakan, sebaiknya bahan yang lentur dan halus sehingga memudahkan sensor untuk dipasang. Jika digunakan glove yang lentur namun berserat, sensor akan rawan rusak karena kemungkinan sensor tersangkut serat menjadi lebih besar.

\section{DAFTAR PUSTAKA}

[1] J. H. van der Lee, R. C. Wagenaar, G. J. Lankhorst, T. W. Vogelaar, W. L. Devillé, and L. M. Bouter, "Forced Use of the Upper Extremity in Chronic Stroke Patients," Stroke, vol. 30, no. 11, pp. 2369-2375, Nov. 1999.

[2] J. W. Burke, M. D. J. McNeill, D. K. Charles, P. J. Morrow, J. H. Crosbie, and S. M. McDonough, "Serious Games for Upper Limb Rehabilitation Following Stroke," in Proceedings of the 2009 Conference in Games and Virtual Worlds for Serious Applications, VS-GAMES 2009, 2009, pp. 103-110.

[3] B. Leon et al., "Grasps recognition and evaluation of stroke patients for supporting rehabilitation therapy," Biomed Res. Int., vol. 2014, 2014.

[4] Ł. Jaworski and R. Karpiński, "Biomechanics of the Human Hand," J. Technol. Exploit. Mech. Eng., vol. 3, no. 1, pp. 28-33, 2017.

[5] A. I. Che-Ani, A. Othman, N. Hamzah, A. D. Rosli, R. Baharudin, and M. F. Abdullah, "Real-Time Finger Hand Movement Capturing Via a Data Hand Glove," ARPN J. Eng. Appl. Sci., vol. 11, no. 7, pp. 4877-4881, 2016.

[6] M. Husni, D. O. Siahaan, H. T. Ciptaningtyas, H. Studiawan, and Y. 
P. Aliarham, "Liquid volume monitoring based on ultrasonic sensor and Arduino microcontroller," in IOP Conference Series: Materials Science and Engineering, 2016, vol. 128, no. 1.

[7] I. Carpinella, J. Jonsdottir, and M. Ferrarin, "Multi-Finger Coordination in Healthy Subjects and Stroke Patients: A Mathematical Modelling Approach," J. Neuroeng. Rehabil., vol. 8, no. 1, p. 19, 2011. 